\title{
Integration and Evaluation of the Impact of Distributed Generation on the Protection System of Distribution Network with DG Using Etap
}

\author{
Modu Abba Gana ${ }^{1, ~ *, ~ U s m a n ~ O t a r u ~ A l i y u ~}{ }^{2}$, Ganiyu Ayinde Bakare ${ }^{2}$ \\ ${ }^{1}$ Department of Electrical \& Electronics Engineering, University of Maiduguri, Maiduguri, Nigeria \\ ${ }^{2}$ Department of Electrical \& Electronics Engineering, ATB University, Bauchi, Nigeria \\ Email address: \\ moduabbagana@yahoo.com (M. A. Gana), u.o.aliyu@yahoo.com (U. O. Aliyu), gabakare@atbu.edu.ng (G. A. Bakare) \\ ${ }^{*}$ Corresponding author
}

To cite this article:

Modu Abba Gana, Usman Otaru Aliyu, Ganiyu Ayinde Bakare. Integration and Evaluation of the Impact of Distributed Generation on the Protection System of Distribution Network with DG Using Etap. Engineering and Applied Sciences. Vol. 4, No. 2, 2019 , pp. 44-51. doi: $10.11648 /$ j.eas. 20190402.13

Received: February 28, 2019; Accepted: May 9, 2019; Published: June 12, 2019

\begin{abstract}
Distributed Generation (DG) has been growing rapidly in deregulated power systems due to their potential solutions to meeting localized demands at distribution level and to mitigate limited transmission capacities from centralized power stations. Penetration of DG into an existing distribution system has so many impacts on the system. Despite the benefits a DG will provide; it has a negative impact on the power system protection, thus affecting both reliability and stability of the system. This paper evaluates the impact of DG on the power protection systems with DG integrated in the systems. IEEE 33 Bus system was modelled in full operational details using ETAP. Protection coordination was carried out using Modified PSO. To investigate the impact of DG on the protection systems, different fault scenario have been simulated with and without DG installed. The fault current level, false tripping, unintentional islanding, and behavior of the existing protection system were investigated considering two scenarios. Case one was the integration of single DG while case two was the integration of two DGs. The type of DG integrated was solar photovoltaic. Simulation results revealed that the fault current level for a 3 phase fault at bus 27 for the system increases by $2.5 \%$ for case one and $24 \%$ for case two. There was unitentational islanding and false tripping as a result of the current contribution from the DG. The sequence of operation of the protective devices clearly showed that there was mis coordination of the protective devices.
\end{abstract}

Keywords: Distributed Generation, Protection System, Modified Particle Swarm Optimization, ETAP

\section{Introduction}

Distributed Generation (DG) has been growing rapidly in deregulated power systems due to their potential solutions to meeting localized demands at distribution level and to mitigate limited transmission capacities from centralized power stations. Penetration of DG into an existing distribution system has so many impacts on the system especially the protection system.

In power systems, protection system can be defined as an art of determining fault in the system with a view to isolate it to ensure continuous operation of the healthy section. Typical distribution systems were designed to operate with radial configuration in which power flows from the source towards the connected customers, so the protection coordination of the radial system is very simple in nature. [1]. The distribution system contains protective devices such as fuses, reclosers, relays and circuit breakers. These protective devices are coordinated in such a way to interrupt the unidirectional flow of the fault current from the source end towards the fault point. Integration of DG within the distribution system. Integration of the DG within a distribution system changed the configuration of power flow for a conventional network from a unidirectional to multidirectional system giving rise issues related with the protection system [2].

The primary objective is to evaluate the impact of DG on the protection of the system. IEEE 33 Bus distribution 
network was used for the study. The optimal placement and sizing of DG was done using Modified Particle swarm optimization and ETAP software was used for the modelling and evaluation of the impact.

\section{Problem Formulation for DG Placement}

In this paper the objective of the placement technique for the DG is to minimize the real power loss and to improve the voltage profile at the distribution level. The real power loss reduction in a distribution system is required for efficient power system operation.

The loss in the system can be calculated using (1) [3], called the 'exact loss formula' given the system operating conditions.

The objective of the placement technique is to minimize the total real power loss and improved voltage profile. Mathematically, the objective function can be written as:

$$
\text { Minimize } P_{L}=\sum_{i=1}^{N}\left|I_{i}\right|^{2} R_{i}
$$

Subject to power balance constraints.

$$
\begin{gathered}
\sum_{i=1}^{N} P_{D G i}=\sum_{i=1}^{N} P_{D i}+P_{L} \\
\text { Voltge Constraints: }\left|V_{i}\right|^{\text {min }} \leq\left|V_{i}\right| \leq\left|V_{i}\right|^{\text {max }} \\
\text { Currents Limits: }\left|I_{i j}\right|\left|I_{i j}\right|^{\text {max }}
\end{gathered}
$$

Where $\mathrm{i}$ is the number of bus, $\mathrm{N}$ is the total number of Buses, $P_{L}$ is the real power loss in the system, $P_{D G i}$ is the real power generation of DG at bus i, $P_{D i}$ is the power demand at bus $\mathrm{i}, I_{i j}$ is the current between buses $\mathrm{i}$ and $\mathrm{j}$ and $R_{i}$ is the resistance. The current $I_{i}$ is determined from the load flow using Hybrid load flow studies Method called Backward Forward and Newton Raphson. For single source network all the power is supplied by the source but with DG that are optimally placed there is going to be reduction in power loss [4]. This reduction in power loss is determined as the difference of the power loss with DG and without DG. Thus, the new power loss in the network with DG is:

$$
\begin{gathered}
P_{L-\text { new }}=\sum_{i=1}^{N}\left|I_{i}^{\text {new }}\right|^{2} R_{i} \\
P_{L-\text { new }}=\sum_{i=1}^{N} I_{i}^{2} R_{i}-2 J I_{i} I_{D G} R_{i}-J I_{i} I_{D G}^{2} R_{i}
\end{gathered}
$$

Where $\mathrm{j}=1$ for a feeder with DG or else $\mathrm{j}=0$ Hence, the power loss reduction value for bus $i$ with DG is obtained by subtracting (5) from (6) as;

$$
\begin{gathered}
\text { PLR }=P_{L-\text { new }}-P_{L} \\
\text { PLRi }=-\sum_{i}^{N}\left(2 J I_{i} I_{D G} R_{i}+J I_{i} I_{D G}^{2}\right) R_{i}
\end{gathered}
$$

The bus that gives the highest value of PLR is selected as the optimal location of DG. The emphasis is to place the DG at a location that will give maximum loss reduction. To obtain the DG current that will give maximum loss reduction, equation (8) is differentiated with respect to IDG and equated to zero, hence the current is given by equation (9) below [5]

$$
\mathrm{I}_{\mathrm{DG} 1}=-\frac{\sum_{i=1}^{n} I_{a i} R_{i}}{\sum_{i=1}^{n} R_{i}}
$$

The procedure is repeated for all the buses in order to obtain the highest power loss reduction value as the DG units are singly located. Assuming there is no significant changes in the voltage as DG units are connected, the power that can be generated is;

$$
P_{D G i}=I_{D G} V_{i}
$$

Where $\mathrm{V}$ is the voltage magnitude of the bus $\mathrm{i}$ and the optimum DG size is obtained from equation (10). The optimal location of the DG is bus $i$ for maximum power loss reduction.

\subsection{Protection System Coordination Using MPSO}

Protection of power system is typically tuned in such a way that only the faulted part of the system gets removed when a fault occurs. This tuning is called protection coordination and this becomes worse when DGs are connected because they can negatively affect the system coordination. [6]

The coordination of OCRs could be achieved by determining two setting values: the pickup current (Ip) and the time dial setting (TDS). The pickup current is the minimum current value for which the relay begins to operate. The TDS adjusts the inverse characteristics of overcurrent device, and hence controls the time delay before relay operates if the fault current reaches a value equal or greater than the pickup current. [7].

The coordination of the relay time settings was done using the following formulae as given in [8] before the integration of DG.

$$
t_{o p}=T D S\left[\frac{A}{\left(\frac{I_{F}}{I_{P}}\right)^{p}-1}+B\right]
$$

Where $t_{o p}$ is the relay operating time in sec, TDS is the time dial setting of the relay, $I_{F}$ is the fault current at the point of corresponding relay breaker location, $I_{P}$ is the pickup current setting for the relay. A, B and $\mathrm{p}$ are the standard constants defined [9] based on relay characteristics as follows.

Table 1. Relay Characteristics (IEEE Standard 1366, 2012).

\begin{tabular}{llll}
\hline Characteristics & A & B & P \\
\hline Moderately Inverse & 0.00515 & 0.114 & 0.02 \\
Very Inverse & 19.61 & 0.491 & 2.0 \\
Extremely Inverse & 28.2 & 0.1217 & 2.0 \\
\hline
\end{tabular}

In the coordination of OCRs, the main aim is to determine the optimum relay parameters including the TDS and Ip settings minimizing the total operation time of all protective devices. Therefore, the main objective function can be stated as the summation of the operating times of all protective relays which needs to be minimized. [10] 


$$
\min \sum_{K=1}^{n}\left(t_{o p} \cdot k\right)
$$

Where $\mathrm{n}$ is the number of relays in the system and $\left(t_{o p} \cdot \mathrm{k}\right)$ is the operating time of the relay $R_{k}$

The objective function is subjected to the following set of constraints.

The requirement of selectivity dictates that when a fault occurs, only the primary relay should operate to trip the fault. If the main relay fails to extinct the fault, the backup relay should clear the fault after a pre specified delay time. It is normally set between 0.2 and $0.5 \mathrm{~s}$. [11] In order to satisfy such requirement, the following constraint must be added.

$$
T_{\text {backup }}-T_{\text {main }} \leq C T I
$$

Where $T_{\text {main }}$ and $T_{\text {backup }}$ are the main and backup relays operation time respectively.

The coordination time interval CTI is the minimum time gap in operation between the primary and backup relays. [12] There is always a range for each relay setting, from which feasible solutions are encountered. Therefore other constraint should be considered on the limits of relay parameters including TDS and Ip settings that can be expressed as follows.

$$
V_{m, n}^{\text {new }}=V_{m, n}^{\text {old }}+\alpha \times \operatorname{rand} n
$$

Where $\alpha$ and $\beta$ are the acceleration constants and randn is random variable with values from 0 to 1 .

The update of the position at new iteration is simply by

$$
P_{m, n}^{\text {new }}=P_{m, n}^{\text {old }}+V_{m, n}^{\text {new }}
$$

Where $\mathrm{m}=1,2 \ldots \mathrm{y}$ and $\mathrm{n}=1,2 \ldots \mathrm{z}$

In order to increase the convergence even further, we can write the update of position in single step as

$$
P_{m, n}^{\text {new }}=(1-\beta) P_{m, n}^{\text {old }}+\beta P_{m, n}^{\text {global }}+\alpha \operatorname{randn}(\mathrm{k})
$$

The values of $\alpha$ is from 0.1 to 0.5 and the value of $\beta$ is from 0.1 to 0.7 .

\subsection{MPSO Implementation}

Optimal DG placement and sizing to reduce the power loss in distribution system using MPSO based method takes the following steps.

Step 1. Read the input data including bus data and branch data, base voltage, base MVA, desired accuracy $\left(1 \times 10^{-3}\right)$ of system.

Step 2. Calculate the power loss of each branch and voltage of each node using forward backward load flow.

Step 3. Set the number of iteration, number of particles, $\alpha$ and $\beta$ values.

Step 4. Generate the initial population randomly for velocity $v_{i}$ and position $p_{i}$.

Step 5. Calculate total power loss for each particle using forward backward load flow.

Step 6. Check out the system constraints.

Step 7. Compare the objective function from individual

$$
\begin{gathered}
T D S_{\min } \leq T D S \leq T D S_{\max } \\
I p_{\min } \leq I p \leq I p_{\max }
\end{gathered}
$$

Where $T D S_{\min }$ and $T D S_{\text {max }}$, and $I p_{\min }$ and $I p_{\max }$ are minimum and maximum limits of the time dial settings and pickup current respectively. The minimum pickup current setting of the relay usually depends on the maximum load current passing through it, while the maximum pickup current setting can be chosen based on the minimum fault current passing inside the coil of the relay.

\subsection{Modified PSO (MPSO)}

Standard PSO uses both current global best and the local best, represented by $P_{m, n}^{\text {global best }}$ and $P_{m, n}^{\text {local best }}$ respectively to update the position and velocity. The purpose of local best is to increase the diversity in the quality solution. However, this same diversity can be simulated with some randomness. There is no need to use individual best until and unless the optimization problem of interest is highly non-linear. In a simplified version of PSO, the global best can accelerate the convergence of an optimization algorithm. [13] Hence the velocity vector at $\mathrm{k}+1$ iteration can be generated by the following equation (16).

best for each particle.

Step 8. Select the particle associated with lowest individual pbest and set this value as gbest.

Step 9. Update the particle's velocity.

Step 10. Update the particle's position.

Step 11. Check the number of iteration reaches to the final value, if it so then go to next step otherwise go step 6 for $\mathrm{k}=$ $\mathrm{k}+1$. Step 12. Print the optimal solution. This will be the best solution for optimal placement and sizing of DG in radial distribution system.

\section{Evaluation of Impact of Distributed Generation}

\subsection{Optimal Location and Size of DG}

Table 2. Optimal location and sizes of DGs.

\begin{tabular}{lllll}
\hline S/No & Configuration & Type of DG & Location (s) & $\begin{array}{l}\text { Size (s) } \\
\text { MW }\end{array}$ \\
\hline 1 & IEEE 33 Bus with 1 DG & Solar & Bus 6 & 2.51 \\
2 & IEEE 33 Bus with 2 DG & Solar & Bus 7 and 16 & $\begin{array}{l}2.14 \text { and } \\
0.654\end{array}$ \\
\hline
\end{tabular}

\subsection{Solar Photovoltaic Design}

Suniva ART245-60 modules of 240 Wp solar panels was used in the design. ART245-60 module is a well-known robust solar cell's type that is designed to be used in grid tied solar projects and power stations. The characteristics of the ART245-60 are taken under STC "Standard Test Conditions" in laboratory environment. The standard conditions are $1000 \mathrm{~W} / \mathrm{m} 2$ irradiation, $25^{\circ} \mathrm{C}$, and 1.5 solar spectrum air 
mass. Basic features of the used modules are presented in Table 2 [14]

$$
\mathrm{V}(\mathrm{T})=\mathrm{V} @ 25 \mathrm{C}(1+\beta \times \Delta \mathrm{T})
$$
2.

Where $\beta$ is the temperature de-rating factor shown in table

Table 2. Basic features of the PV modules.

\begin{tabular}{lll}
\hline S/No & Parameter & Rating \\
\hline 1. & Maximum power & $240 \mathrm{~W}$ \\
2. & Voltage @ maximum power point & $30.9 \mathrm{~V}$ \\
3. & Current @ maximum power point & $7.95 \mathrm{~A}$ \\
4. & Open circuit voltage & $37.4 \mathrm{~V}$ \\
5. & Short circuit current & $8.44 \mathrm{~A}$ \\
6. & Cells per module & 60 \\
7. & $\beta\left(\right.$ Voltage de-rating factor $\left.\left(\operatorname{Voc} \% /{ }^{\circ} \mathrm{C}\right)\right)$ & -0.332 \\
8. & $\alpha\left(\right.$ Current de-rating factor $\left.\left(\operatorname{Isc} \% /{ }^{\circ} \mathrm{C}\right)\right)$ & 0.035 \\
9. & $\gamma\left(\right.$ Power de-rating factor $\left.\left(\operatorname{Pmax} \% /{ }^{\circ} \mathrm{C}\right)\right)$ & -0.465 \\
\hline
\end{tabular}

Table 3. Features of the $A B B 1 M W$ central inverter.

\begin{tabular}{lll}
\hline S/No & Parameter & Rating \\
\hline 1. & Rated power & $1000 \mathrm{KW}$ \\
2. & Maximum power & $1200 \mathrm{~kW}$ \\
3. & DC voltage range (MPPT) & $600-850 \mathrm{~V}$ \\
4. & Maximum DC voltage & $1100 \mathrm{~V}$ \\
5. & Maximum DC current & $1710 \mathrm{~A}$ \\
\hline
\end{tabular}

\begin{tabular}{lll}
\hline S/No & Parameter & Rating \\
\hline 6. & DC inputs & $8-20 \mathrm{~A}$ \\
7. & Nominal AC voltage & $400 \mathrm{~V}$ \\
8. & Nominal AC current & $1445 \mathrm{~A}$ \\
\hline
\end{tabular}

\subsection{Modelling IEEE 33 Bus Distribution Network}

IEEE test system has 33 bus and 32 sections with the total load of 3.72 MW and 2.3 MVAR. Base MVA 100, conductor type is All Aluminum Alloy Conductor (AAAC), Base voltage $11 \mathrm{kV}$, Resistance of 0.55 per $\mathrm{km}$ and reactance of $0.35 \mathrm{ohm}$ per $\mathrm{km}$. [6] In ETAP IEEE 33 Bus Model was created in edit mode with the configuration status set to normal. ETAP's electrical system diagram is a one line representation of balanced three phase system. [15]. It was constructed graphically by connecting the buses, branches, transformers and protective devices from the one line diagram edit toolbar. Elements were graphically connected to the buses by using info page of the device property editor. The property editor was opened by double clicking on the element. The engineering properties of the element such as ratings, settings, loading, connection etc. were assigned using the editor. The DG (solar PV) were designed and placed at the optimal location as suggested by the MPSO. The ETAP Model of the system is shown in Figure 1.

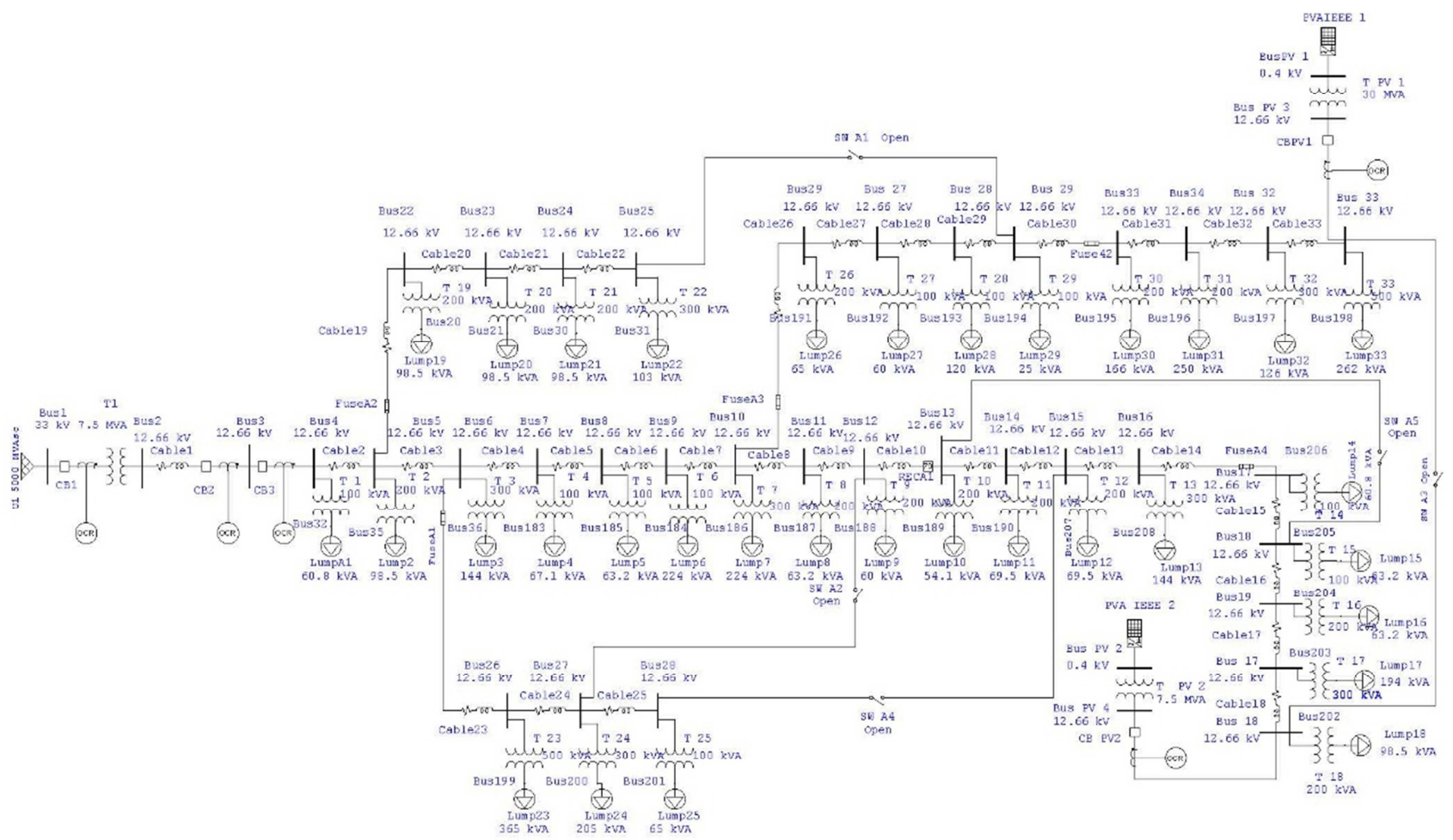

Figure 1. ETAP Model of IEEE 33 Bus test system with protective devices and switches.

\section{Results for Evaluation of Impact of Distributed Generation}

\subsection{Short Circuit Current Level Simulation Results}

A short circuit analysis was carried out to find out fault current at different buses with and without DG installed. It is clear from result in Table 3, that after the introduction of DG, fault current level has changed. The result is shown in Tables 3 and 4 plotted in Figures 2 to 5. 
Table 3. Fault current level with $1 D G$ and without $D G$.

\begin{tabular}{|c|c|c|c|c|c|c|c|c|c|c|}
\hline \multirow{2}{*}{$\begin{array}{l}\text { Distribution } \\
\text { Network }\end{array}$} & \multirow{2}{*}{ DG Location } & \multirow{2}{*}{ Fault At } & \multicolumn{4}{|c|}{ Fault current (kA) With out DG } & \multicolumn{4}{|c|}{ Fault current (kA) With 1 DG } \\
\hline & & & 3LLL & 2LLG & $2 \mathrm{LL}$ & $1 \mathrm{LG}$ & 3LLL & 2LLG & $2 \mathrm{LL}$ & 1LG \\
\hline IEEE 33 Bus System & Bus 28 & Bus 27 & 3.554 & 3.481 & 3.078 & 2.470 & 3.614 & 4.037 & 3.130 & 3.682 \\
\hline IEEE 33 Bus System & Bus 28 & Bus 29 & 3.120 & 3.025 & 2.702 & 2.096 & 3.186 & 3.624 & 2.759 & 3.448 \\
\hline
\end{tabular}

Table 4. Fault current level with $2 D G$ and without $D G$.

\begin{tabular}{|c|c|c|c|c|c|c|c|c|c|c|}
\hline \multirow{2}{*}{$\begin{array}{l}\text { Distribution } \\
\text { System }\end{array}$} & \multirow{2}{*}{ DG Location (s) } & \multirow{2}{*}{ Fault At } & \multicolumn{4}{|c|}{ Fault current (kA) With out DG } & \multicolumn{4}{|c|}{ Fault current (kA) With 2 DG } \\
\hline & & & 3LLL & 2LLG & $2 \mathrm{LL}$ & $1 \mathrm{LG}$ & 3LLL & 2LLG & $2 \mathbf{L L}$ & $1 \mathrm{LG}$ \\
\hline $\begin{array}{l}\text { IEEE } 33 \text { Bus } \\
\text { System }\end{array}$ & Bus $18 \& 33$ & Bus 17 & 2.024 & 1.933 & 1.768 & 1.251 & 4.177 & 5.358 & 3.618 & 5.312 \\
\hline $\begin{array}{l}\text { IEEE } 33 \text { Bus } \\
\text { System }\end{array}$ & Bus $18 \& 33$ & Bus 32 & 2.963 & 2.856 & 2.566 & 1.917 & 3.667 & 5.741 & 3.176 & 5.297 \\
\hline
\end{tabular}

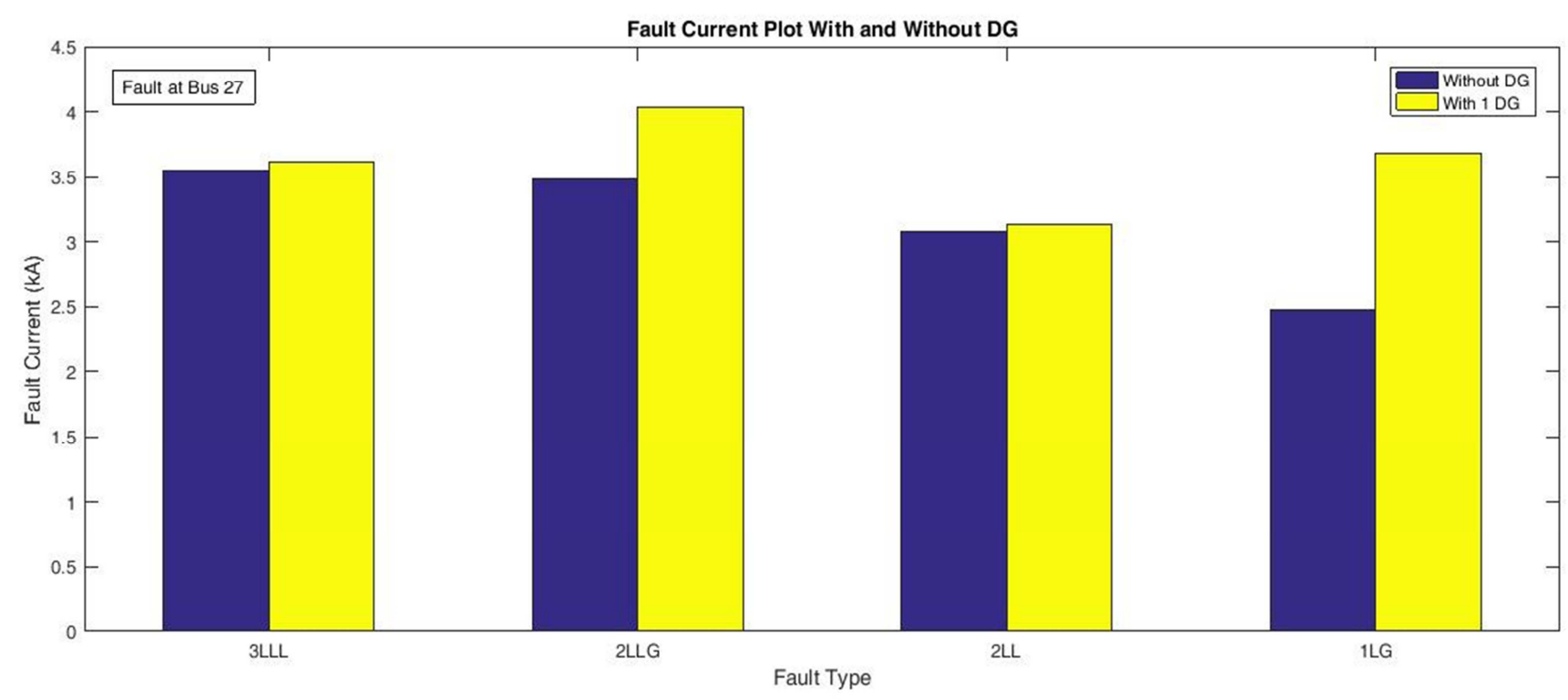

(a)

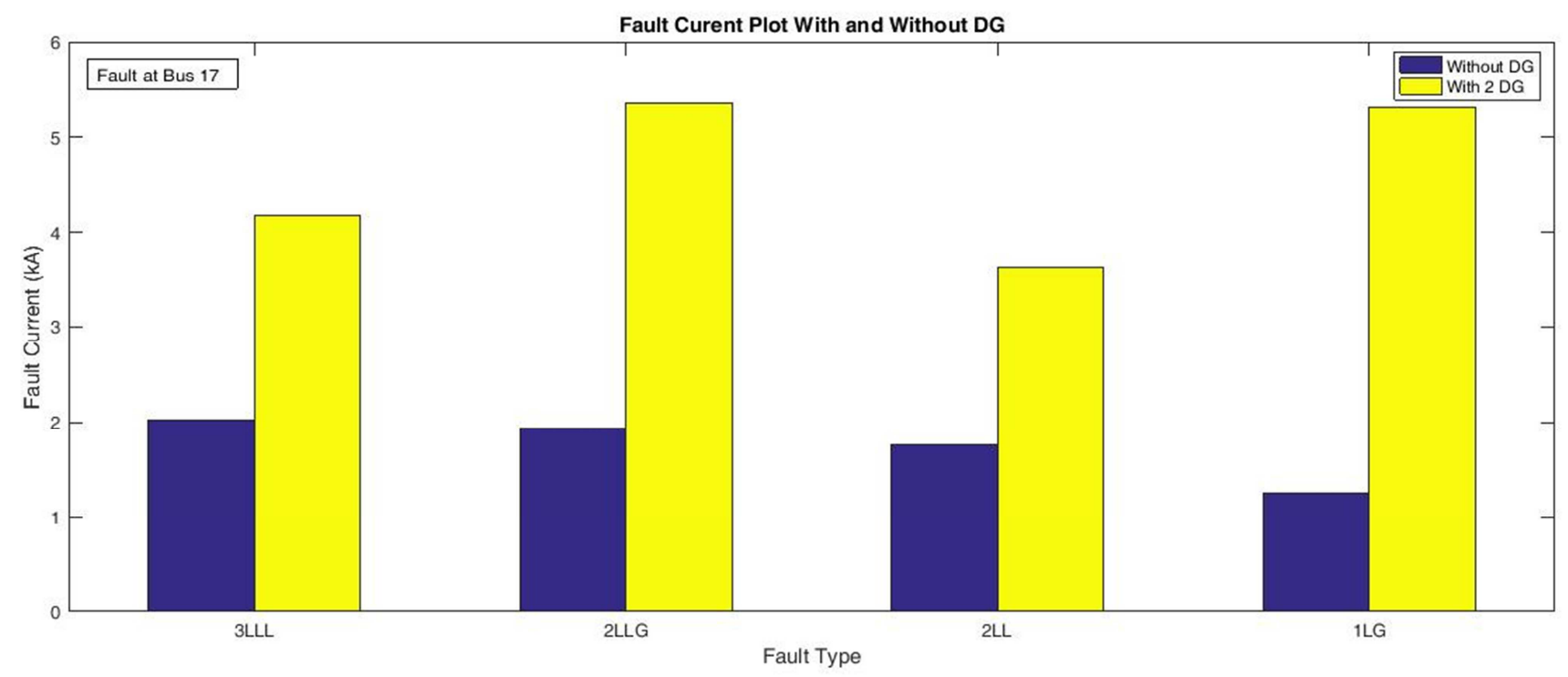

(b)

Figure 2. (a) Fault Current for IEEE 33 Bus system with 1DGat Bus 28 and fault at Bus 27 (b) fault at Bus 29. 


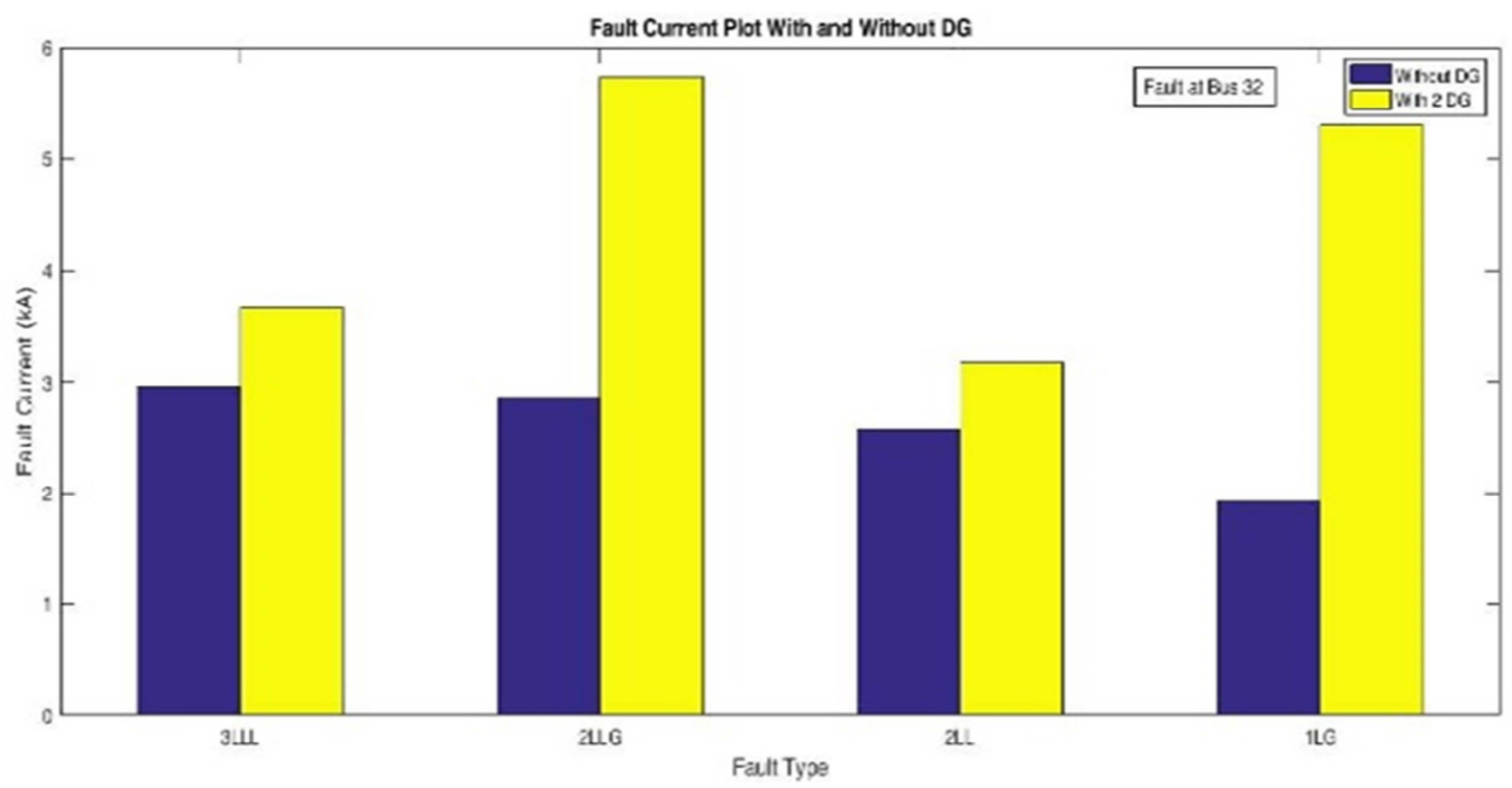

(a)

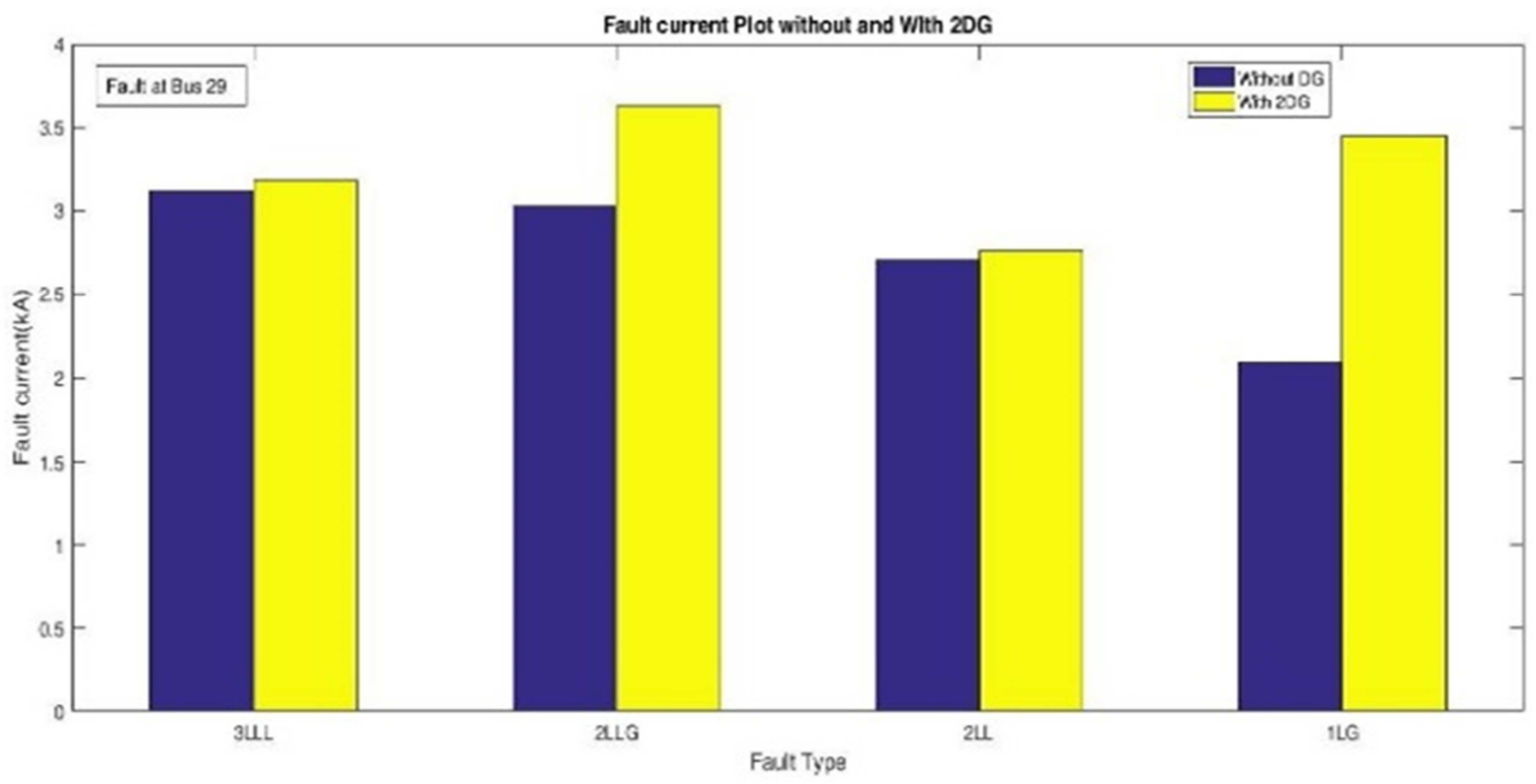

(b)

Figure 3. (a) Fault Current for IEEE 33 Bus with 2 DG at Buses 18 \& 33 and fault at Bus 17 (b) fault at Bus 32.

\subsection{Coordination Simulation Result}

To investigate the impact of DG on protection coordination, the networks was modelled and simulated using ETAP software. The sequence of operation of the protective devices are shown in Table 5 for a three phase to ground fault.

Table 5. Sequence of Operation of Protective Devices.

\begin{tabular}{lllllll}
\hline \multirow{2}{*}{ Power system } & \multirow{2}{*}{ DG Location (s) } & Faulted & \multicolumn{2}{l}{ Actual tripping } & Correct Tripping \\
\cline { 3 - 6 } & & Bus & Primary & Backup & Primary & Backup \\
\hline IEEE 33 Bus with 1 DG & Bus 28 & Bus 29 & Fuse A3 & DG1 Relay, Main Relay & Fuse A3 & Main Relay \\
IEEE 33 Bus with 2 DG & Bus 18 \& 33 & Bus 19 & Fuse A4 & Lateral Fuse 1, Main Relay & Fuse A4 & Recloser 1, Main Relay \\
IEEE 33 Bus with 2 DG & Bus 18 \& 33 & Bus 34 & Fuse A3 & DG2 Relay, Main Relay & Fuse A3 & Main Relay \\
\hline
\end{tabular}




\subsection{Ferro Resonance Result}

To verify the existence of Ferro resonance in the distribution network when there is circuit breaker or fuse failure, we simulated part of the network using PSCAD. At the 33/11 kV injection substation with 7.5 MVA power transformer, switch was opened on phase B at the time of $0.1 \mathrm{~s}$ and closed at $0.5 \mathrm{~s}$. The bus voltage and the Transformer primary and secondary voltages were plotted in Figures 4 and 5.

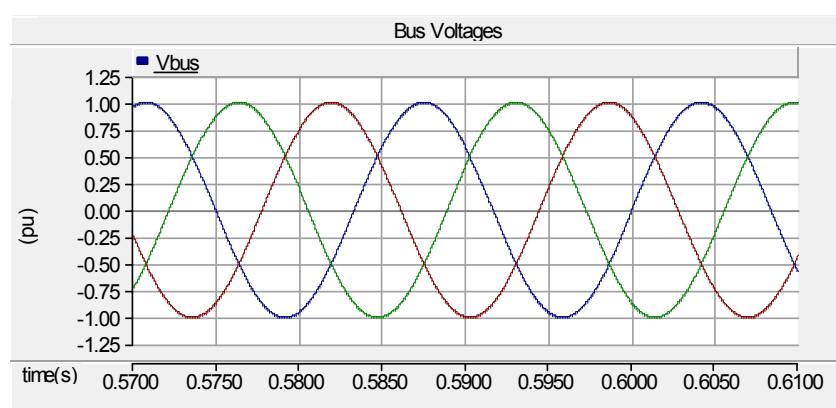

Figure 4. Transformer Bus Voltage.

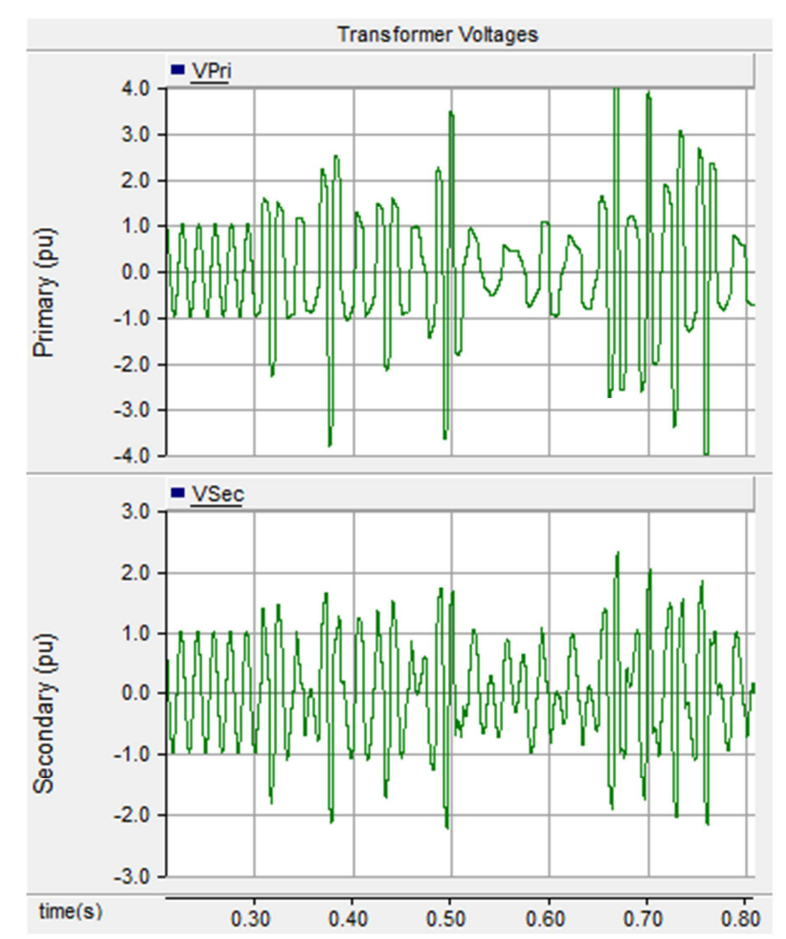

Figure 5. Transformer Primary and Secondary Voltage 5. Discussions.

\section{Discussions}

\subsection{Fault Current Level}

In this research, effort has been to study the impact of distributed Generation on power protection system of a distribution network with distributed energy resources. From the analysis it is clear that DG negatively affects the distribution system by the changing the radial nature of the network and the fault current. As the number of DG increases the fault current also increases since the fault current is sum of the current contribution from all the sources. However, in a situation where the DG is placed at the extreme of the feeder it reduces the reach of the relays. This is due to the fact that DGs that are placed at the extreme of the feeder increase the equivalent impedance of the feeder which decreases the fault current.

\subsection{Coordination}

As a result of the change in the fault current, issues like mis coordination, improper sequence of operation, islanding and false tripping of the protective devices has been observed as reported in Table 5. The initial settings of the protective devices can no longer hold as the Time dial setting, pick up current and the operating time of the devices are function of the fault current.

\subsection{Ferro Resonance}

There was also an instance of Ferro resonance when the malfunction of protective device was studied. When a fuse that protects a transformer in the three phases do not trigger simultaneously or a breaker malfunction, it happens that a transformer is connected only via two phases for a short time. Then, the capacitance of the cable is in series with the transformer inductance what could cause distorted / high voltages and currents due to resonance conditions which may lead to damage to customer equipment or transformer.

\section{Conclusions}

This work investigates the protection issues that can arise when DG is integrated in to distribution network using ETAP software. Firstly, solar DGs with optimal size were integrated in to a model of IEEE 33 Bus test system in ETAP. Secondly, different fault scenarios with and without DG were simulated. The result showed that DG integration can change the fault current level and, consequently, coordination of protective devices. Unintentional Islanding, sympathetic tripping and Ferro resonance can also occur.

\section{References}

[1] Adefarati, T., \& Bansal, R. C. (2016). Integration of renewable distributed generators into the distribution system: a review. IET Renewable Power Generation, 10 (7), pp. 873-884.

[2] MCV Suresh and Belwin Edward J (2017)" Optimal placement of distributed generation in Distribution systems by using shuffled frog leaping algorithm" ARPN Journal of Engineering and Applied Sciences Volume. 12, No. 3.

[3] Moravej Z. (2012) optimal coordination of distance and overcurrent relays in series compensated systems based on MAPSO. Energy conversion and Management. Vol $56 \mathrm{pp}$ $140-151$. 
[4] Sadeh, J. M. B. (2010). Effect of Distributed Generation Capacity on the Coordination of Protection System of Distribution Network. Azad University, IEEE, Iran.

[5] Silva J. A., H. B. Funmilayo, K. L. Butler-Purry, (2007), "Impact of Distributed Generation on the IEEE 34 Node Radial Test Feeder with Overcurrent Protection", 39th North American Power Symposium, 49-57.

[6] Osabohien R. W and Uhunmwangho R. (2018) Reducing the impact of DG on distribution networks protection with reverse power relay. Nigrerian Journal of Technology. Volume 30 (1) pp. 209-215.

[7] Semih C. I. and Aysen B. A. (2017) Effects of Distributed Generation on Overcurrent Relay Coordination and an Adaptive Protection Scheme. IOP Conference Series: Earth and Environmental Science, Volume 73.

[8] Alberts, J. A., \& de Kock, J. A. (2017). "Impact on power factor by small scale renewable energy generation". In Domestic Use of Energy (DUE), International Conference on power systems and control. pp. 146-151.

[9] Kumar D S, Radhakrishnan B M, Srinivasan D and Reindl T (2015) IEEE International Conference on Fuzzy Systems (Turkey: Istanbul) pp. 1-6.
[10] Saha D, Datta A and Das P (2016) Optimal coordination of directional overcurrent relays in power systems using symbiotic organism search optimization technique IET Generation., Transmission. \& Distribution. Voluem10 pp. 2681-88.

[11] Soman S A (2016) PSM Setting and Phase Relay Coordination (Tutorial) URL: http://www.nptel.ac.in/courses/108101039/16.

[12] Pradeep M V and Rama R. (2018) A rev. Power and Energy Society General Meeting Conversion and Delivery of Electrical Energy in the 21st Cent. (USA: Pittsburgh) pp. 1-7 Anudevi. S. Vinayak. N. Shet (2017) "Distribution Network with optimal DG Placement and Protection Impacts: Review Analysis" International Journal of Electrical and Electronics Engineering (SSRG - IJEEE) Volume 4 Issue $2 \mathrm{M}$. Sedighizadeh, M. Fallahnejad, M. R. Alemi, M. Omidvaran and D. Arzaghi-haris (2010) "Optimal Placement of Distributed Generation Using Combination of PSO and Clonal Algorithm", IEEE International Conference on Power and Energy, Malaysia Mohanty S R, Singh R K and Choudhary N $\mathrm{K}$ (2015) Coordination of overcurrent relay in distributed system for different network configuration Journal of Power and Energy Engineering. Volume 3 pp. 1-9. 